\title{
Genetic analysis of the Müllerian-inhibiting substance signal transduction pathway in mammalian sexual differentiation
}

\author{
Yuji Mishina, ${ }^{1}$ Rodolfo Rey, ${ }^{2}$ Milton J. Finegold, ${ }^{3}$ Martin M. Matzuk, ${ }^{3}$ Nathalie Josso, ${ }^{2}$ \\ Richard L. Cate, ${ }^{4}$ and Richard R. Behringer ${ }^{1,5}$ \\ ${ }^{1}$ Department of Molecular Genetics, The University of Texas M.D. Anderson Cancer Center, Houston, Texas 77030 USA; \\ ${ }^{2}$ Unité de Recherches sur l'Endocrinologie du Développement, INSERM U-293, Ecole Normale Supérieure, Département de \\ Biologie, 92120 Montrouge, France; ${ }^{3}$ Department of Pathology, Baylor College of Medicine, Houston, Texas 77030 USA; \\ ${ }^{4}$ Biogen, Incorporated, Cambridge, Massachusetts 02142 USA
}

Müllerian-inhibiting substance (MIS) is a member of the transforming growth factor- $\beta$ (TGF- $\beta$ ) gene family. MIS expression in males causes the regression of the Müllerian ducts, an essential process in male sexual differentiation. Recently, an MIS type II receptor gene has been isolated that is expressed during embryogenesis in mesenchymal cells adjacent to the Müllerian duct epithelium and in Sertoli and granulosa cells of the fetal and adult, male and female gonads, respectively. MIS receptor mutant males develop as internal pseudohermaphrodites, possessing a complete male reproductive tract and also a uterus and oviducts, a phenocopy of MIS ligand-deficient male mice. They express both MIS mRNA and protein, showing that ligand was present, but target organs were hormone-insensitive. All produce sperm, but the majority were infertile because the presence of their female reproductive organs blocks sperm transfer into females. Focal seminiferous tubule atrophy accompanied by Leydig cell hyperplasia was observed and began as early as 2 months of age. The phenotype of MIS ligand/MIS receptor double mutant males was indistinguishable from those of each single mutant. MIS receptor/ $\alpha$-inhibin double mutant males developed testicular stromal tumors and large fluid-filled uteri that were identical in phenotype to MIS ligand/ $\alpha$-inhibin double mutant males. These studies provide in vivo evidence that MIS is the only ligand of the MIS type II receptor, in contrast to the complexity of other TGF- $\beta$ gene family signaling pathways.

[Key Words: TGF- $\beta$ gene family; anti-Müllerian hormone; testis; tumorigenesis]

Received July 19, 1996; revised version accepted August 23, 1996.

Male sexual differentiation in eutherian mammals is regulated by two hormones produced during embryogenesis (Jost 1953). Initially, Sertoli cells of the fetal testis produce Müllerian-inhibiting substance (MIS), also called anti-Müllerian hormone (AMH), that causes the regression of the Müllerian ducts, the anlagen of the female reproductive organs, the uterus, oviducts, and upper portion of the vagina (for review, see Josso et al. 1993). Subsequently, testosterone produced by Leydig cells stimulates the differentiation of the Wolffian ducts into vas deferens, epididymides, and seminal vesicles and masculinizes the external genitalia. Female fetuses do not produce either hormone, which allows the development of the Müllerian duct derivatives and the passive regression of the Wolffian ducts. However, MIS is expressed in fe-

${ }^{5}$ Corresponding author. males after birth in the granulosa cells of the ovary, although at much lower levels (Vigier et al. 1984).

Male mice that lack MIS develop as internal pseudohermaphrodites (Behringer et al. 1994). They have testes that are morphologically normal and correctly descended. In addition, the Wolffian duct system is fully differentiated and functional. However, these MIS ligand-deficient males also have a uterus and oviducts. Although MIS ligand-deficient males can produce functional sperm, most are infertile because of the physical constraints imposed by the development of both male and female reproductive organs. A small number of MIS ligand-deficient males older than 10 weeks of age develop Leydig cell hyperplasia, and one mouse had a Leydig cell tumor, suggesting that MIS may negatively regulate Leydig cell proliferation. Although MIS is expressed in a regulated manner in postnatal females, MIS ligand-deficient females are normal and fertile. Human 
males that lack MIS also develop as internal pseudohermaphrodites with uterine and oviductal tissues, a condition known as persistent Müllerian duct syndrome (PMDS) (Guerrier et al. 1989). In contrast to MIS liganddeficient mice, PMDS human males often have undescended testes. The mutant phenotypes of the MIS ligand-deficient mice and PMDS humans highlight the highly specific role of MIS in the regression of the Müllerian ducts during male sexual differentiation.

Transgenic mice that ectopically express high levels of human MIS (hMIS) throughout development have mutant phenotypes restricted to sexual differentiation and the reproductive organs (Behringer et al. 1990). Female hMIS transgenic mice lack a uterus, oviducts, and ovaries. Ovaries initially form, but lose germ cells. Subsequently, the somatic cells of the germ cell-depleted ovary transdifferentiate into tubule-like structures reminiscent of the seminiferous tubules of the male gonad. Most of the hMIS transgenic males developed normally and were fertile. A proportion of male transgenic mice that express very high levels of hMIS are not masculinized (Behringer et al. 1990). Externally, they appear female, and internally, their testes are undescended and the Wolffian duct system is not differentiated, suggesting a defect in androgen biosynthesis. Subsequent studies showed that male transgenic mice that ectopically express MIS have depressed levels of circulating testosterone, suggesting that excess hMIS can alter Leydig cell function (Lyet et al. 1995). The tissue-specific MIS-induced mutant phenotypes of transgenic mice with high levels of circulating MIS suggest that the limiting factor in this signal transduction pathway is the MIS receptor.
Thus, the characterization of the MIS receptor is an important step in understanding the MIS signal transduction pathway in mammalian sexual differentiation and reproductive development.

TGF- $\beta$ family members signal through two membrane-bound serine/threonine kinases (Wrana et al. 1994). Type II receptors bind ligand when expressed alone but require the presence of the type I receptor for signaling (for review, see Massagué et al. 1994). Recently, MIS type II receptor genes have been isolated from rat Sertoli cell (Baarends et al. 1994; Teixeira et al. 1996) and rabbit fetal ovary cDNA (di Clemente et al. 1994) libraries. The human gene has been cloned from a prepubertal testis cDNA library (Imbeaud et al. 1995) and a human genomic library. Sequence comparisons suggest that the rat, rabbit, and human genes are homologs. The expression of the type II receptor gene is localized to the mesenchymal cells adjacent to the Müllerian duct epithelium during embryogenesis and Sertoli cells and granulosa cells in fetal and adult testes and ovaries, respectively (Baarends et al. 1994, 1995a,b; di Clemente et al. 1994; Teixeira et al. 1996). In addition, receptor mRNA was detected in the gravid uterus (Teixeira et al. 1996). MIS-specific binding with a dissociation constant of 2.48-2.55 nM has been demonstrated in COS cells transfected with the human MIS type II receptor cDNA (Imbeaud et al. 1995). On the basis of its structure, expression pattern, and in vitro binding data, this gene encodes a type II receptor for MIS.

To investigate the role of this type II receptor in the MIS signal transduction pathway of male sexual differentiation, MIS type II receptor mutant mice were gener-
Figure 1. Mutation of the MIS type II receptor locus. $(A)$ Strategy for targeted mutation of the MIS type II receptor locus. (Top) Structure of the MIS type II receptor locus. Boxes represent exons. The exon which encodes the transmembrane region is represented by a solid box (exon 4). The sizes of the restriction fragments detected by the indicated probes in wild-type DNA are shown above the locus. (Middle) The gene-targeting vector. (Open boxes) MIS type II receptor homologous regions used in the targeting vector; NEO, PGK-neo expression cassette that introduces novel SacI and EcoRV restriction sites; TK, MCl-tk expression cassette for negative selection. The arrows beneath NEO and TK indicate the direction of transcription of each cassette. The unique Southern probes are shown. (Bottom) Structure of the targeted locus. The sizes of the restriction fragments detected by the Southern probes in the targeted locus are shown above the locus. $(E)$ EcoRI; (H) HindIII; (S) SacI; (V) $E c o R V ;(X) X b a I .(B)$ Southern analysis of genomic DNA isolated from ES cell lines. Correct targeting events are shown for two different ES clones (E8 and H8). (Left) EcoRI-EcoRV-digested ES cell DNA hybridized with the 5' probe. The 4.7-kb wild-type and 6.6-kb mutant bands are shown. (Right) SacI-digested ES cell DNA hybridized with the 3' probe. The 8.5-kb wild-type and 5.3-kb mutant bands are shown. AB-1, wild-type ES cell line. $(C)$ Southern blot showing genotypes of newborn mice from a heterozygote mating. EcoRI-EcoRV-digested tail DNA hybridized with the $5^{\prime}$ probe. The $4.7-\mathrm{kb}$ wild-type and 6.6 -kb mutant bands are shown. $(+1+1$ Wild-type; $(+1-)$ heterozygous mutant; $(-1-)$ homozygous mutant.
B

\section{$A$}
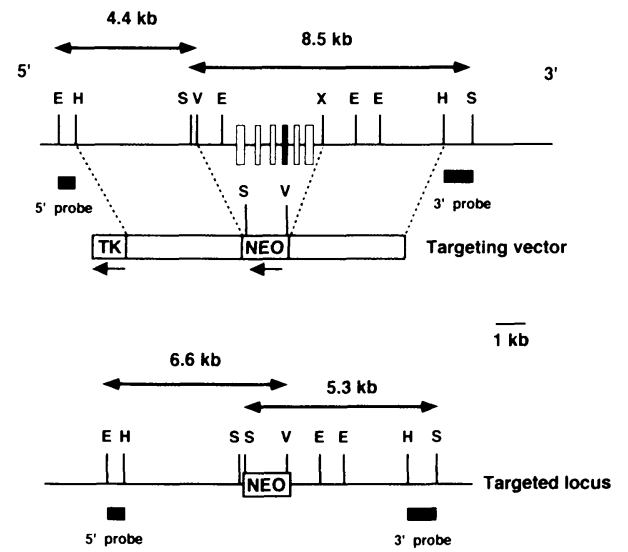

C 5' probe

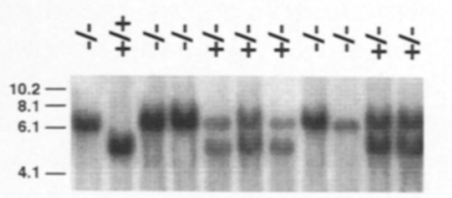


ated by gene targeting in embryonic stem (ES) cells. Analysis of the mutant phenotypes of MIS receptor homozygous mutants, MIS ligand/MIS receptor double mutants, and MIS receptor/ $\alpha$-inhibin double mutants suggests that in vivo MIS is the only ligand of the MIS type II receptor. These findings are in contrast to the complexity observed for other TGF- $\beta$ family signaling pathways.

\section{Results}

Generation of a MIS type II receptor mutant allele in the mouse germ-line

To mutate the MIS type II receptor gene in mouse ES cells, we generated a targeting vector that deletes $4.4 \mathrm{~kb}$ of the receptor locus including the first six exons, by replacing them with a neomycin-resistance expression cassette (Fig. 1A). When the vector recombines with the endogenous gene, novel EcoRV and SacI sites are introduced (Fig. 1A). Correctly targeted clones can, therefore, be detected by the presence of an additional $6.6-\mathrm{kb} \mathrm{mu-}$ tant fragment when digested with $E c o$ RI/EcoRV and hybridized with a $5^{\prime}$ probe external to the region of vector homology or by the presence of a 5.3-kb mutant band when digested with SaclI and hybridized with a 3' probe external to the region of vector homology (Fig. 1B). Correct targeting deletes $\sim 2.0 \mathrm{~kb}$ of 5 '-flanking sequence and the first six exons of the MIS type II receptor locus that encode the translation initiation start codon, the signal peptide, the transmembrane region, and $\sim 20 \%$ of the serine/threonine kinase domain. It was predicted that this mutation would functionally inactivate the MIS receptor. Two correctly targeted ES clones successfully contributed to the germ-lines of chimeric mice generated by blastocyst injection. The phenotypes of the MIS receptor mutant mice from two independently derived ES cell clones were identical. The phenotype of the MIS type II receptor mutation, examined on either a C57BL/ $6 \times 129 / \mathrm{SvEv}$ mixed genetic background and a $129 /$ SvEv inbred genetic background, was essentially the same.

\section{Male MIS receptor mutants develop as internal pseudohermaphrodites}

Both male and female mice heterozygous for the MIS receptor mutation appeared normal and were fertile. Males and females homozygous for the MIS receptor mutation were recovered from matings between heterozygotes at the predicted Mendelian ratios (Fig. 1C). Thus, MIS receptor homozygous mutant mice were viable. Because altered expression of MIS can change the external sexual phenotype of transgenic mice, the sex chromosome genotype of the MIS receptor mutants was assessed by use of a Y chromosome-specific probe (Behringer et al. 1990). In each case, the sexual phenotype of the MIS receptor mutants matched the Y chromosome genotype.

All MIS receptor homozygous mutant females were normal and fertile, as is the case for MIS ligand-deficient females (Behringer et al. 1994). All of the MIS receptor homozygous mutant male mice had testes of normal size that were fully descended into the scrotal sac. Male-specific reproductive tissues derived from the Wolffian ducts had differentiated normally. These MIS receptor mutant males also developed Müllerian duct derivatives, including a uterus, oviducts, and partial vagina that were superimposed upon the male reproductive system (Fig. $2 A, B)$. These gross anatomical abnormalities were identical to those of the reproductive tracts of MIS liganddeficient male mice (Fig. 2C). Because these male MIS receptor mutant mice had testes and both Wolffian and Müllerian duct-derived tissues, they are internal pseudohermaphrodites.

To confirm that this mutant phenotype was caused by the lack of MIS signal transduction but not by the lack of MIS itself, MIS mRNA and protein were measured in the MIS receptor-deficient mutants. In males, MIS levels are highest before birth in the fetal testes and persist after birth but at lower levels (Hacker et al. 1995). In females, low levels of MIS are produced in the ovary after birth (Münsterberg and Lovell-Badge 1991). Reverse transcription-polymerase chain reaction (RT-PCR) was used to examine the expression of MIS mRNA in embryonic day 13.5 (E13.5) gonads (Fig. 3). As expected, E13.5 females did not express detectable levels of MIS mRNA. In contrast, both heterozygous and homozygous E13.5 MIS receptor-deficient males expressed MIS mRNA. Therefore, at the stage when Müllerian duct regression should be actively occurring in MIS receptor-deficient males, MIS mRNA is present. In addition, serum levels of MIS protein in MIS receptor-deficient mutants and controls at 9
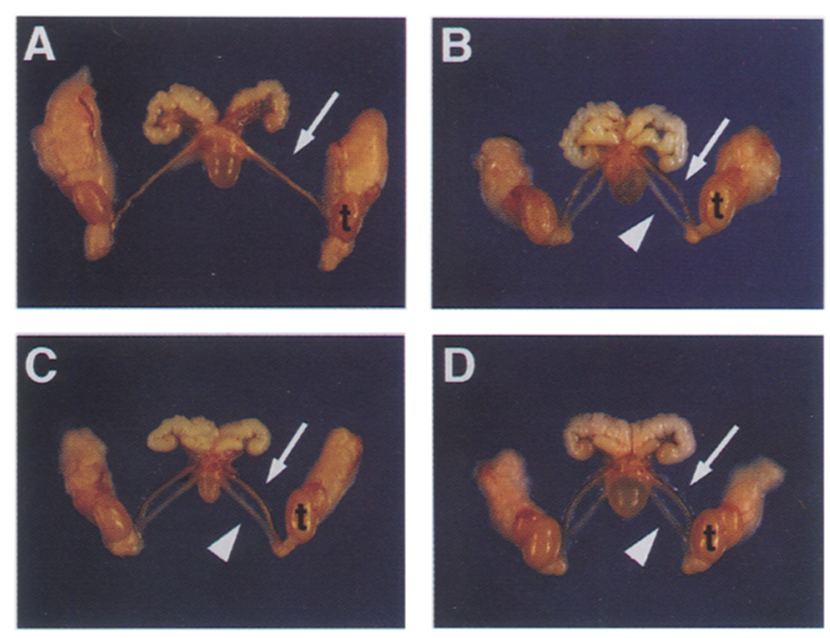

Figure 2. Male reproductive tracts of control, MIS receptordeficient, MIS ligand-deficient and MIS ligand/MIS receptor double mutant mice. $(A)$ control; $(B)$ MIS receptor homozygous mutant; $(C)$ MIS ligand homozygous mutant; $(D)$ MIS ligand/ MIS receptor double mutant. In the mutants, the uterine horns (arrowheads) and vas deferens (arrows) parallel each other down to the testes because of a common connective tissue. In these dissections, the connective tissue has been cut to reveal the male and female reproductive organs. $(t)$ Testis. 


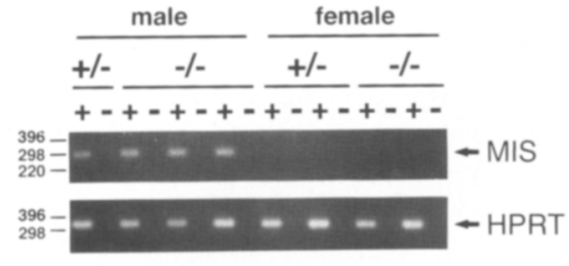

Figure 3. Expression of MIS mRNA in MIS type II receptordeficient male fetuses. Total RNA prepared from E13.5 urogenital ridges was assayed by RT-PCR. PCR primers specific for MIS to generate a 280-bp fragment (upper panel) and primers for HPRT to generate a 354-bp fragment (lower panel) were used. Ethidium bromide-stained agarose gels showing PCR products. $1+1-\mid$ Heterozygous mutant; $|-1-|$ homozygous mutant; $|+|$ PCR amplification after reverse transcription; $(-\mid$ PCR amplification without reverse transcription.

or 10 days after birth were measured by a noncompetitive, solid-phase, double-antibody enzyme-linked immunoabsorbent assay (ELISA). There were no significant differences in the levels of MIS among MIS receptor homozygous mutant, heterozygous, or wild-type males or females (Table 1). These results show that MIS was expressed and regulated in a normal manner in both male and female MIS receptor-deficient mice. Thus, the presence of MIS ligand and the persistence of Müllerian ductderived tissues in MIS receptor-deficient males demonstrates that the Müllerian ducts in these animals are insensitive to the action of MIS, because of the targeted mutation of the MIS receptor gene. These in vivo results show that the gene mutated in this study encodes the MIS receptor.

\section{Fertility of MIS receptor mutant mice}

MIS ligand and MIS receptor are expressed in Sertoli cells of the testis and granulosa cells of the postnatal ovary, suggesting that the MIS signal transduction pathway may also regulate gametogenesis. Indeed, exposure of fetal ovaries to MIS in vitro or in vivo leads to germ cell loss (Vigier et al. 1987; Behringer et al. 1990). Therefore, MIS receptor-deficient mice might be expected to have fertility defects. To test this hypothesis, matings were established between MIS receptor homozygous or heterozygous mutant males and wild-type females. In addition, MIS receptor homozygous or heterozygous mutant females were bred with wild-type males. All of the males heterozygous for the MIS receptor mutation immediately impregnated their mates. However, less than half 17 out of 19) of the MIS receptor homozygous mutant males sired offspring. The infertile MIS receptor homozygous mutant males mated with females and produced vaginal plugs, but no sperm was found in the plugs. In addition, the MIS receptor homozygous mutant males that were fertile sired fewer litters compared with controls, suggesting that even though they were fertile, their ability to sire offspring was compromised.

Histological analysis of the testes of 1.5- to 6-monthold MIS receptor homozygous mutant males that were infertile revealed no consistent differences in spermatogenesis in comparison with the fertile MIS receptor homozygous mutants, heterozygotes, or wild-type males (data not shown). These results suggest that signaling through the MIS receptor is not essential for male germ cell development and that the infertility observed in the MIS receptor homozygous mutant males is not caused by factors intrinsic to the male germ cells. The initial infertility of the mutants is probably caused by the physical blockage of sperm transport into the female reproductive tract caused by the presence of the Müllerian duct derivatives as observed in MIS ligand deficient males (Behringer et al. 1994). Older MIS receptor homozygous mutant males (6-11 months old) developed testicular pathology that also contributed to their inability to sire offspring (see below).

In contrast to the fertility defects observed in the MIS receptor-deficient males, all of the MIS receptor homozygous mutant females $(n>20)$ were fertile. Normal folliculogenesis was observed in the ovaries of the MIS receptor-deficient females, suggesting that signaling through the MIS receptor is not essential for female germ cell development or folliculogenesis.

\section{Seminiferous tubule atrophy and Leydig cell hyperplasia in MIS receptor mutant mice}

By 2 months of age, MIS receptor mutants displayed focal atrophy of the germinal epithelium in a few seminiferous tubules just below the tunica albuginea (Table 2). This was associated with the vacuolization of Sertoli cells and proliferation of Leydig cells in the immediate vicinity (Fig. 4A). Such focal abnormalities, with good preservation of spermatogenesis in the majority of the tubules, were observed in 12 of 27 MIS receptor mutants between 1.5 and 10 months of age. In two of six older mice (9-10 months), the atrophy was much greater and spermatogenesis was greatly reduced (Fig. 4C; Table 2). Foci of dystrophic calcification were numerous and there

Table 1. Serum levels of MIS in $d 9$ and d10 offspring

\begin{tabular}{lrrr}
\hline & \multicolumn{3}{c}{ MIS $(\mathrm{ng} / \mathrm{ml} \pm$ s.D. } \\
\cline { 2 - 4 } Sex & \multicolumn{1}{c}{$+1+$} & $+/-$ & $-1-$ \\
\hline Male & $108.82 \pm 34.74(8)^{\mathrm{a}}$ & $104.93 \pm 34.00(19)$ & $115.00 \pm 37.65(13)$ \\
Female & $8.50 \pm 9.00(11)$ & $8.84 \pm 8.13(14)$ & $8.25 \pm 12.44(10)$ \\
\hline
\end{tabular}

${ }^{a}$ Numbers in parentheses represent number of animals. 
Table 2. Pathology of the testes of MIS receptor mutants

\begin{tabular}{ccc}
\hline $\begin{array}{l}\text { Age } \\
\text { (months) }\end{array}$ & $\begin{array}{l}\text { Normal } \\
\text { (no. of animals) }\end{array}$ & $\begin{array}{l}\text { Focal germinal epithelium } \\
\text { atrophy }\end{array}$ \\
\hline $1.5-4$ & 3 & $3(2)^{\mathrm{a}}$ \\
$5-7$ & 3 & $6(6)$ \\
$8-11$ & $6^{\mathrm{b}}$ & $6(6)^{\mathrm{c}}$ \\
\hline
\end{tabular}

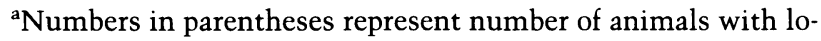
calized Leydig cell hyperplasia.

b Two 8- to 10-month-old mice had a single focus of calcification in the seminiferous tubules.

${ }^{\mathrm{c}}$ Two 10-month-old mice had significant loss of spermatogenesis and diffuse Leydig cell hyperplasia.

was correspondingly diffuse Leydig cell hyperplasia. None of the MIS receptor heterozygotes displayed any testicular abnormalities.

\section{MIS ligand/MIS receptor double mutant mice}

The MIS receptor mutation yields a phenotype in male mice that is a phenocopy of the male MIS ligand mutant phenotype, suggesting that for Müllerian duct regression, MIS is the only functional ligand of the MIS type II receptor. To further examine this hypothesis, we generated MIS ligand/MIS receptor double mutant mice. We predicted that if the MIS ligand only interacted with the MIS receptor and that if the receptor only interacted with the MIS ligand, then the elimination of both the MIS ligand and the MIS receptor should result in no novel mutant phenotypes.

MIS ligand/MIS receptor compound heterozygous mutant males and females were normal and fertile. These compound heterozygotes were interbred to generate mice homozygous mutant for both the MIS ligand and MIS receptor mutations. As shown in Figure 2D, the gross anatomy of the reproductive tissues from a MIS ligand/MIS receptor double homozygous mutant male is indistinguishable from those of MIS ligand- or MIS receptor-deficient male mice (Fig. 2B,C). Histological analysis showed no major differences in spermatogenesis in these double homozygous mutant males in comparison to controls (data not shown). The fertility of MIS ligand/ MIS receptor double homozygous mutant males was examined by mating with wild-type females. Six out of six MIS ligand/MIS receptor double mutant males were infertile. All of the MIS ligand/MIS receptor double homozygous mutant females $(n>10)$ were fertile and produced litters of normal size at normal intervals. These results clearly show that the mutant phenotypes of the MIS receptor mutation and the MIS ligand/MIS receptor compound mutations are phenocopies of the MIS ligand mutant phenotype. This indicates that MIS is the only ligand for the MIS type II receptor.

\section{Synergistic action of MIS and inhibin signaling pathways in testicular tumorigenesis}

$\alpha$-Inhibin is a member of the TGF- $\beta$ gene family that is expressed in multiple tissues including the somatic cells of the male and female gonads (Vale et al. 1990). Male and female $\alpha$-inhibin-deficient mice develop gonadal tumors of Sertoli and granulosa cell origin (Matzuk et al. 1992). Because MIS and inhibins are related hormones, are produced by the same gonadal cell types, and both loss-of-function mutants develop gonadal abnormalities, it was postulated that there might be cross talk between the MIS and the inhibin signaling pathways. This hypothesis was examined previously by generating MIS ligand/inhibin double homozygous mutant mice (Matzuk et al. 1995a). MIS ligand/inhibin double homozygous mutant male mice developed testicular tumors and large fluid-filled uteri. Their testes developed Sertoli/ granulosa cell tumors and Leydig cell neoplasia earlier than $\alpha$-inhibin-deficient and MIS ligand-deficient controls, suggesting that MIS and inhibins synergize to influence testicular tumorigenesis (Matzuk et al. 1995a). To understand the level of interaction between these two signaling pathways, MIS receptor/ $\alpha$-inhibin doublemutant mice were generated.

The most prominent phenotype observed in the MIS receptor $/ \alpha$-inhibin double homozygous mutant males was a dilated fluid-filled uterus and large testicular tumors, that were identical in phenotype to those observed in MIS ligand/ $\alpha$-inhibin double homozygous mutant male mice (Fig. 5A,B). $\alpha$-Inhibin-deficient mice also develop testicular tumors but the tumors are more hemorrhagic and never as large as the tumors in either MIS ligand $/ \alpha$-inhibin or MIS receptor $/ \alpha$-inhibin double homozygous mutant males (Fig. 5C D). Histologically, multifocal Leydig cell neoplasia and multifocal Sertoli/ granulosa cell tumors were observed in the testes of MIS receptor/ $\alpha$-inhibin double homozygous mutant males. This phenotype is the same as observed in the testes of MIS ligand $/ \alpha$-inhibin double homozygous mutant males (Matzuk et al. 1995a).

Interestingly, unilateral stromal tumors were found in the testes of three MIS receptor homozygous mutants that were 5-7 months old. They also carried heterozygous mutations for $\alpha$-inhibin or MIS. The tumors differed slightly from those of inhibin mutants by being smaller, less hemorrhagic and containing nests of Leydig cells in addition to undifferentiated and granulosa celllike foci (Fig. 4D). None of the six MIS receptor heterozygotes and $\alpha$-inhibin wild-type mice in this series or any of the $\sim 40 \alpha$-inhibin heterozygotes over 12 months of age in our earlier studies (Matzuk et al. 1995a) had stromal tumors. The mice mentioned above were examined on a $\mathrm{C} 57 \mathrm{Bl} / 6 \times 129 / \mathrm{SvEv}$ mixed genetic background. The low penetrance of these stromal tumors in the MIS receptor homozygous mutant males may be caused by genetic background influences or stochastic mechanisms.

Taken together, these observations suggest that MIS signaling can influence the development of Sertoli/granulosa cell tumors initiated by the absence of inhibins and that inhibins can influence the development of Leydig cell neoplasia initiated by the absence of MIS signaling. The observation that the testicular tumors that developed in the MIS receptor/ $\alpha$-inhibin double homozygous 
Figure 4. Histopathology of MIS receptor mutant testes. $(A)$ Focal germinal epithelial atrophy and vacuolar degeneration of Sertoli cells in a subcapsular seminiferous tubule of a 2-monthold MIS receptor homozygous mutant. Focal hyperplasia of Leydig cells is seen between the abnormal tubules. There is normal spermatogenesis in the adajacent tubules at the top of the photograph. Magnification, $200 \times$. (B) Normal testis (right) and epididymis (left) of a 9-monthold control mouse (MIS receptor heterozygote). There is uniform spermatogenesis in all tubules and mature spermatozoa fill the epididymal ducts. Magnification, $100 \times .(C)$ Testes and epididymis from a 9-month-old MIS receptor homozygous mutant showing alterations in germinal activity ranging from total absence of spermatogenesis in some tubules to abnormal patterns in others (right) and of spermatozoa in the epididymis (left). Focal calcification is present in a degenerated tubule centrally. Magnification, $100 \times .(D)$ Testes from a 6-month-old
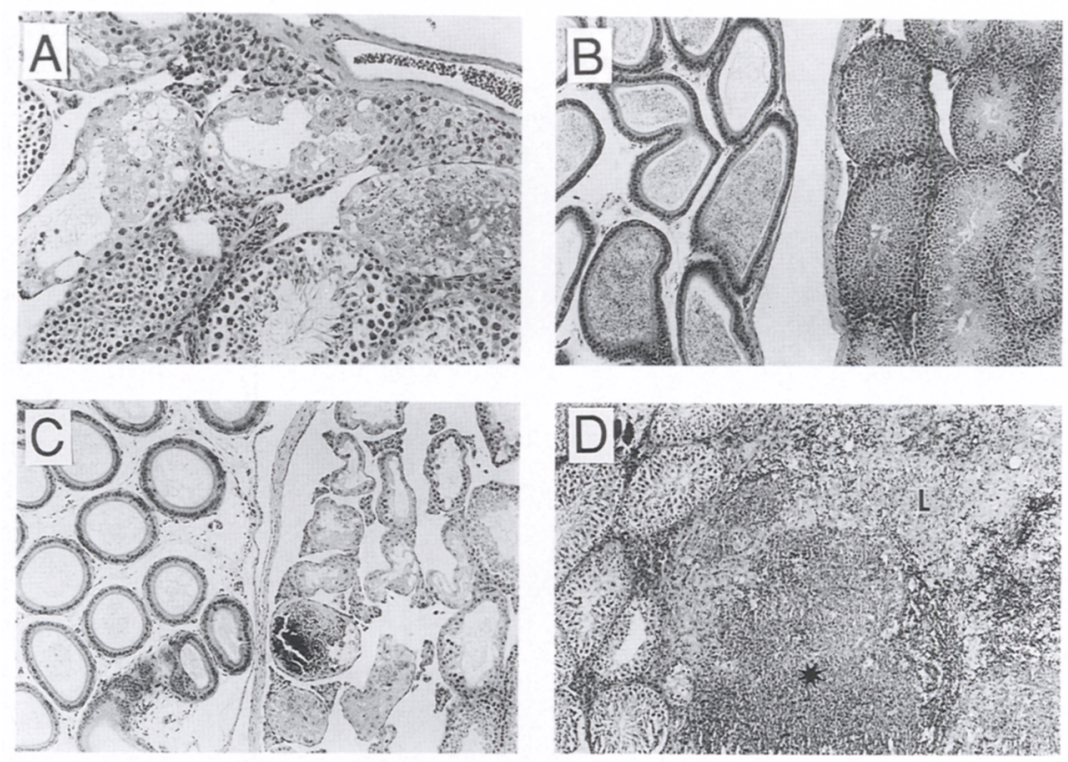
MIS receptor homozygous mutant, MIS ligand heterozygote containing a non encapsulated stromal tumor that compresses adjacent seminiferous tubules. The tumor consists mainly of undifferentiated small cells $\left({ }^{*}\right)$ but also includes foci of Leydig cell proliferation (L). Magnification, 100×.

mutant males were identical in phenotype to the testicular tumors that develop in the MIS ligand $/ \alpha$-inhibin double homozygous mutant males provides further evidence that MIS is the only ligand for the MIS receptor. In addition, these results suggest that the synergism between the MIS and inhibin signaling pathways occurs downstream of each receptor, not between ligands and receptors.

\section{Discussion}

\section{The MIS type II receptor gene}

Targeted mutagenesis of the MIS type II receptor gene leads to the development of males with internal pseudohermaphroditism, infertility, seminiferous tubule atrophy, and Leydig cell hyperplasia. Males that are otherwise normal have a uterus and oviducts, a phenotype that is identical to MIS ligand mutant male mice (Behringer et al. 1994). However, in contrast to MIS ligand mutant mice, MIS receptor mutants synthesize MIS ligand but possess target organs that are insensitive to its action. In addition, MIS ligand/MIS receptor double mutant males have the same mutant phenotype as either of the single mutants. Furthermore, MIS receptor $/ \alpha$-inhibin double mutant males develop dilated fluid-filled uteri and rapidly growing testicular tumors, a phenotype that is identical to male MIS ligand $/ \alpha$-inhibin double mutant mice (Matzuk et al. 1995a). Female mice that lack MIS are normal and fertile as are the female MIS receptor mutant mice and the female MIS ligand/MIS receptor double mutant mice (Behringer et al. 1994). These genetic studies demonstrate that the MIS type II receptor gene functions in vivo to mediate MIS signaling.

In humans, the molecular basis of the PMDS syn-
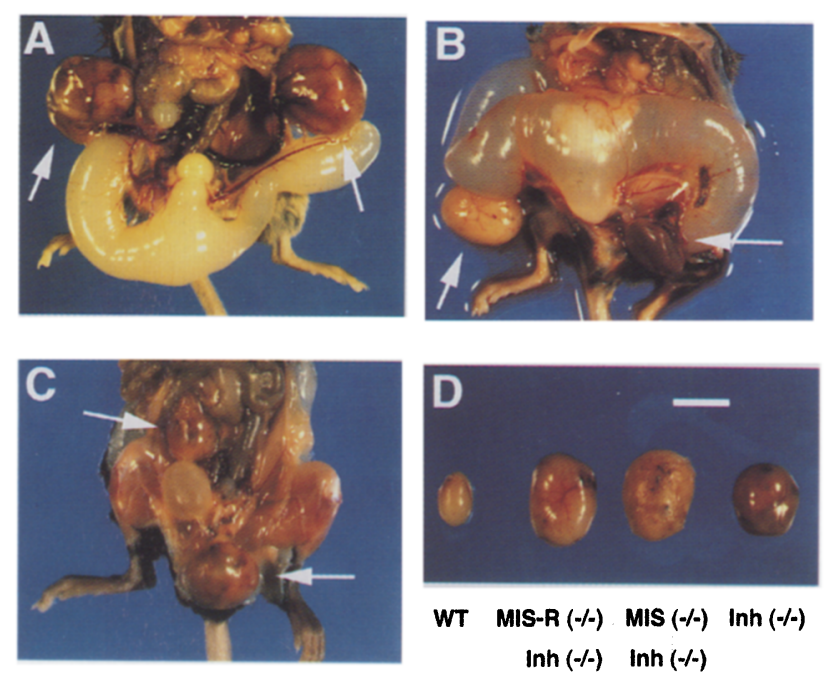

Figure 5. Gross analysis of the reproductive tracts and testes of MIS receptor $/ \alpha$-inhibin double mutant male mice. Abdominal views of 4-month-old mutant male mice. $(A)$ MIS receptor/ $\alpha-$ inhibin double mutant; $(B)$ MIS ligand/ $\alpha$-inhibin double mutant; $(C) \alpha$-inhibin homozygous mutant. Note the larger testicular tumors (arrows) and expanded fluid-filled uteri in $A$ and $B$. $(D)$ Testes from 4-month-old male mice. MIS ligand-deficient testes were normal in size like the wild-type testis shown at the left. The $\alpha$-inhibin-deficient testis on the right was enlarged and hemorrhagic because of an invasive Sertoli/granulosa tumor. The very large size of the two testes in the middle from MIS ligand/ $\alpha$-inhibin and MIS receptor/ $\alpha$-inhibin double-mutant mice were less hemorrhagic. In the testicular tumors of MIS receptor/ $\alpha$-inhibin double-mutant males, multifocal Leydig cell neoplasia and multifocal Sertoli/granulosa cell tumors were found that were identical to the tumors of ligand $/ \alpha$-inhibin double-mutant males. Bar, $1 \mathrm{~cm}$. 
drome is heterogeneous (Imbeaud et al. 1996). In AMHnegative cases, MIS serum levels are low or undetectable, biopsied testicular tissue has no anti-Müllerian activity and mutations of the MIS gene have been detected (Knebelmann et al. 1991; Carré-Eusèbe et al. 1992; Imbeaud et al. 1994). In contrast $\mathrm{AMH}$-positive patients have serum MIS levels at the upper limit of normal and testicular biopsies are able to induce the regression of fetal rat Müllerian ducts in culture. Testicular biopsies of PMDS dogs also exhibit anti-Müllerian activity (Meyers-Wallen et al. 1989). The insensitivity of MIS target organs to normal levels of the hormone suggests that a mutation of the MIS receptor could be involved and indeed, several have been detected by single strand conformation polymorphism (SSCP) screening in AMH positive patients (Imbeaud et al. 1995, 1996). Interestingly, patients with MIS gene and MIS type II receptor gene mutations shared the same clinical phenotype. Thus, the mouse and human studies complement each other, and suggest that in mammals the MIS signaling pathway is simple.

The simplicity of the MIS signaling pathway relative to the complexity of other TGF- $\beta$ family signaling pathways

In mammals, the MIS ligand mutant male phenotype is a phenocopy of the MIS type II receptor mutant male phenotype (Knebelmann et al. 1991; Behringer et al. 1994; Imbeaud et al. 1994, 1995, 1996). These findings are in contrast to those of other TGF- $\beta$ family ligands and receptors whose genes have been mutated in mice. Activins are composed of $\beta_{A}$ and $\beta_{B}$ subunits /Vale et al. 1990). Activin- $\beta_{B}$ mutant mice are viable with defects in eyelid development and female reproduction (Vassali et al. 1994). Activin- $\beta_{\text {A }}$ mutant mice die within 24 hours after birth, lack whiskers and the lower, incisors and also have defects in the secondary palate, including cleft palate (Matzuk et al. 1995b). Activin $\beta_{A} / \beta_{B}$ double mutant mice have also been generated that cannot produce activins or inhibins (Matzuk et al. 1995b). The mutant phenotype of these activin $\beta_{A} / \beta_{B}$ double mutant mice is the addition of the activin- $\beta_{A}$ and activin- $\beta_{B}$ mutant phenotypes. In contrast, most activin type II receptor mutant mice are viable (Matzuk et al. 1995c). A minority of the activin receptor mutants have a variably expressed hypoplasia of the mandible that secondarily leads to an absence of incisors and cleft palate. These animals also have eyelid closure defects. The surviving male activin receptor mutants are fertile, but they are delayed in their ability to generate sufficient amounts of functional sperm. Female activin receptor mutants are infertile and have no estrous cycle. Significantly, few of the activin type II receptor mutant phenotypes overlapped with the mutant phenotypes of the activin ligand mutants, suggesting that in mammals, activin signaling pathways are complex.

Somewhat similar findings have been observed for BMP ligand and receptor mutant mice. BMP-2 mutant mice die during embryogenesis at approximately E8.5 with a variable mutant phenotype. The predominant abnormality is a failure of the proamniotic canal to close. Subsequently, heart abnormalities also develop (Zhang and Bradley 1996). BMP-4 mutant mice die during embryogenesis with a highly variable phenotype, that is, some BMP-4 mutants can develop to the early somite stage whereas the most severely affected ones are arrested at the egg-cylinder stage and produce some extraembryonic mesoderm (Winnier et al. 1995). BMP-2/ BMP-4 receptor mutant embryos do not form any mesodermal tissues and die by E8.5. In contrast with the variable mutant phenotypes of the BMP-2 and BMP-4 ligand mutants, the phenotype of the BMP-2/BMP-4 type I receptor mutant mice is consistent even when examined on multiple genetic backgrounds (Mishina et al. 1995). Although the most severe phenotype of the BMP-4 mutants approximate the BMP-2/BMP-4 type I receptor mutant phenotype, it is not a phenocopy.

Thus, in mammals at least the activin and the BMP2/BMP-4 signaling pathways are complex. This may not be surprising because there are multiple type I and type II receptors for activins and BMP-2 and BMP-4 that have been defined by biochemical studies (Kingsley 1994). Furthermore, the contrasting findings between activin and BMP-2 and BMP-4 ligand mutant mice and mice mutant for their respective receptors may also be attributable in part to crosstalk between ligands and receptors. TGF- $\beta$ family ligands are structurally related to each other (Kingsley 1994) and it has been shown that one type of receptor can interact with several classes of ligands (Attisano et al. 1993; Koenig et al. 1994; Suzuki et al. 1994; ten Dijke et al. 1994; Yamaji et al. 1994). In addition, other studies indicate that one ligand can interact with several classes of receptors (Attisano et al. 1992, 1993; ten Dijke et al. 1994). As clearly shown here, unlike the complexity of other TGF- $\beta$ family signaling pathways, the MIS signaling pathway is simple with MIS being the only ligand which interacts with the MIS type II receptor.

The role of MIS signaling in Müllerian duct regression and the testis

Although the MIS type II receptor is expressed in both testes and ovaries (Baarends et al. 1994, 1995a,b; di Clemente et al. 1994; Teixeira et al. 1996), our loss-offunction studies for MIS and the MIS receptor show that MIS signaling is not essential for either gonadal or germcell development (Behringer et al. 1994). Whereas signaling through this receptor is essential for the regression of the Müllerian ducts during male sexual differentiation, these findings convincingly show that in the mouse, MIS signals are not essential for testicular morphogenesis and descent, and male and female gametogenesis. Thus, the perinatal loss of germ cells and subsequent loss of the ovary that was observed in female transgenic mice that overexpress hMIS may be caused by a crosstalk between MIS and other TGF- $\beta$ family receptors. Alternatively, it is possible that the MIS type II receptor itself may interact with high levels of MIS to transduce an abnormal 
signal to cause gonadal and/or germ cell abnormalities. The generation of transgenic mice that overexpress MIS in a MIS receptor mutant genetic background may provide clues to distinguish between these two possibilities.

A significant proportion of MIS receptor mutant males develop focal atrophy of the germinal epithelium associated with Leydig cell hyperplasia in the testis at older ages. In some cases, tubule atrophy was observed that was not associated with Leydig cell hyperplasia. Because MIS type II receptor expression has been shown only in Sertoli cells within the testis, the simplest interpretation of these results is that autocrine signaling by MIS would regulate Sertoli cell factors acting on neighboring Leydig and germ cells. MIS ligand deficient mice have Leydig cell hyperplasia and though not mentioned previously, also focal atrophy of the germinal epithelium (Behringer et al. 1994). Reexamination of nine MIS ligand mutant males older than 1.5 months detected this pathology in three of the animals. These results suggest a continuing role for MIS signals in the function of the testis during the period of reproduction.

Previously, we showed that the MIS and the inhibin signaling pathways can synergize to influence testicular tumorigenesis by generating mice that lacked both ligands (Matzuk et al. 1995a). It was not clear at what level MIS and inhibins were synergizing to influence tumorigenesis. The results presented here suggest that the synergism between the MIS and inhibin signaling pathways is not caused by interactions between inhibins and the MIS type II receptor. Therefore, the interaction between these two signaling pathways must be downstream of the receptors. Indeed, the interaction may be between different testicular cell types.

\section{The MIS type I receptor and downstream targets of MIS signaling}

TGF $\beta$ family receptor complexes are heteromers that contain type I and type II receptor molecules (Attisano et al. 1993; Franzén et al. 1993; Wrana et al. 1994; Franzén et al. 1995). Therefore, there should be a type I receptor that complexes with the MIS type II receptor to transduce signals that are essential for Müllerian duct regression and normal testicular function. Because the MIS type II receptor is only detected in MIS target organs, all tissue specificity for the action of MIS can be accounted for by the expression of the type II receptor. Therefore, although the MIS type I receptor must at least be expressed in the same cell types that express the MIS type II receptor, the MIS type I receptor may be more widely expressed and shared with other TGF- $\beta$ family type II receptors.

Recently, a type I TGF- $\beta$ family receptor has been isolated called ActR-1, Tsk7L, SKR1, ALK-2 or R1 that can bind both activin and TGF- $\beta$ (Ebner et al. 1993; He et al. 1993; Matsuzaki et al. 1993; ten Dijke et al. 1993). This type I receptor is expressed widely during embryogenesis and in adult tissues (He et al. 1993; ten Dijke et al. 1993). During rat embryogenesis, it is expressed in the mesenchymal cells adjacent to the Müllerian duct epithelium, suggesting that it might function as a MIS type I receptor.

Ultimately, it will be very interesting to determine the downstream targets of the MIS signaling pathway for Müllerian duct regression. Humans with PMDS who are MIS positive but have no apparent alterations in their MIS type II receptors may have mutations in genes encoding downstream effectors of MIS signaling. Indeed, whereas in humans, MIS maps to chromosome 19 (Cohen-Haguenauer et al. 1987) and the MIS type II receptor maps to chromosome 12 (Imbeaud et al. 1995; Visser et al. 1995), X-chromosome-linked transmission of PMDS has been reported in two families (Sloan and Walsh 1976; Naguib et al. 1989). Therefore, these two PMDS cases may be caused by a mutation in a third gene possibly functioning downstream of MIS. These human families and the MIS ligand and MIS type II receptor mutant mice will serve as valuable genetic resources to isolate the downstream targets of this differentiation pathway of male sexual development.

\section{Materials and methods} Mutagenesis of the MIS type II receptor gene in mouse ES
cells

A $129 /$ SvEv mouse genomic library was screened with the extracellular-encoded region of the rabbit MIS type II receptor cDNA (di Clemente et al. 1994). Four positive $\lambda$-phage clones were isolated, and the genomic organization of the MIS type II receptor was characterized (Y. Mishina, R. Tizzard, B. Pathak, N. Copeland, N. Jenkins, R. Cate, and R. Behringer, in prep.). A 3.9-kb HindIII-EcoRV 5' fragment and a 4.2-kb XbaI-HindIII 3' fragment were used to construct a replacement gene targeting vector (Fig. 1A). A PGKneobpA resistance expression cassette was inserted in reverse orientation relative to the direction of the MIS receptor transcription between the two MIS receptor homologous regions (Soriano et al. 1991). An MCltkpA herpes simplex virus thymidine kinase expression cassette was added onto the short arm of homology to enrich for homologous recombinants by negative selection with 1-(2-deoxy-2-fluoro- $\beta$-Darabinofuranosyl)-S-iodouracil (FIAU) (Mansour et al. 1988). The targeting vector can be linearized at a unique NotI site outside of the homology. Twenty-five micrograms of linearized targeting vector was electroporated into $10^{7} \mathrm{AB}-1 \mathrm{ES}$ cells that were subsequently cultured in the presence of G418 and FIAU on mitotically inactivated STO fibroblasts (McMahon and Bradley 1990; Soriano et al. 1991). Four hundred G418/FIAU-resistant ES clones were initially screened by SacI digestion and hybridized with a unique 3' probe external to the region of vector homology. Correctly targeted clones were then expanded for further Southern blot analysis by EcoRI-EcoRV digestion and hybridization with a unique $5^{\prime}$ probe external to the vector homology. Two correctly targeted ES clones were identified.

Generation of chimeric mice and germline transmission of the MIS type II receptor mutant allele

Two of the MIS type II receptor mutant ES clones were microinjected into $\mathrm{C} 57 \mathrm{BL} / 6 \mathrm{~J}$ blastocysts, and the resulting chimeric embryos were transferred to the uterine horns of day 2.5 pseudopregnant foster mothers (Bradley 1987). Chimeras were identified among the resulting progeny by their agouti fur (ES derived) and were subsequently bred with C57BL/ 6 mates. Two of the mutant ES clones (E8 and H8) were found to be capable of 
contributing to the germlines of chimeric mice. Tail DNA from the agouti pups that resulted from these matings was analyzed by Southern blot with either of the probes used to identify the MIS receptor heterozygotes. Chimeras were also bred with 129/ SvEv females to establish the MIS receptor mutation on a 129/ SvEv inbred genetic background.

Generation of MIS ligand/MIS receptor double mutant mice and $\alpha$-inhibin/MIS receptor double mutant mice

To generate MIS ligand/MIS receptor double mutant mice, MIS ligand mutant mice were first bred with MIS receptor mutants to generate mice heterozygous for both mutations. The MIS ligand genotype was determined as described (Behringer et al. 1994). These double heterozygous mice were interbred to generate mice homozygous mutant for both genes. Similarly, to generate $\alpha$-inhibin/MIS receptor double mutant mice, $\alpha$-inhibin mutant mice (Matzuk et al. 1992) were bred with MIS receptor mutants to generate mice heterozygous for both mutations. The $\alpha$-inhibin genotype was determined as described (Matzuk et al. 1992). These double heterozygous mice were interbred to generate mice homozygous mutant for both genes.

\section{Histological analysis}

Male reproductive tracts and testes were processed for histological analysis as described by Kaufman (1990). Briefly, the tissues were fixed in $10 \%$ buffered formalin, dehydrated, and embedded in paraffin. Four-micrometer-thick sections were cut and stained with hematoxylin and eosin.

\section{MIS RT-PCR analysis}

Total RNA was isolated from the gonads of E13.5 embryos by the acid-guanidinium thiocyanate phenol-chloroform method (Chomczynski and Sacchi 1987). RNA was reverse transcribed with oligo(dT) $12-18 \mathrm{mer}$ primer and $\mathrm{M}-\mathrm{MLV}$ reverse transcriptase (Gibco BRL) at $25^{\circ} \mathrm{C}$ for $10 \mathrm{~min}$ and $42^{\circ} \mathrm{C}$ for $50 \mathrm{~min}$. The resulting cDNA was amplified by PCR with the MIS specific primers 5'-GTCTGAACAGCTATGAGTATG-3' and 5'CGCTGGTCCAGAGTATAGCAC-3' and the HPRT specific primers 5'-CCTGCTGGATTACATTAAAGCACT-3' and 5'-GTCAAGGCATATCCAACAACAAA- 3 ' and the reaction products were separated on $3 \%$ agarose gels and visualized by ethidium bromide staining.

\section{Measurement of serum MIS}

Serum MIS was measured by ELISA . Briefly, polystyrene plates Immulon-II (Dynatech, Guyancourt, France) were coated with an anti recombinant human MIS polyclonal antibody raised in rabbit at $10 \mu \mathrm{g} / \mathrm{ml}$. Serum was incubated at four different dilutions $(1: 4,1: 8,1: 16$, and $1: 32)$ in phosphate-buffered saline containing $1 \%$ BSA (PBS-1\% BSA) for $1 \mathrm{hr}$. The plates were successively exposed to an anti recombinant human MIS polyclonal antibody raised in guinea pig at $5 \mu \mathrm{g} / \mathrm{ml}$ in PBS-1\% BSA and to an alkaline phosphatase-conjugated anti-guinea pig IgG antibody (Rockland, Gilbertsville, PA) diluted 1:1000 in Tris-buffered saline containing $1 \%$ BSA. A color reaction was demonstrated with p-nitrophenyl phosphate (Sigma, St. Louis, MO) 1 $\mathrm{mg} / \mathrm{ml}$ in diethanolamin/ $\mathrm{HCl} 10 \mathrm{mM}, \mathrm{MgCl}_{2} 1 \mathrm{~mm}$ at $\mathrm{pH} 9.8$. Absorbance at $405 \mathrm{~nm}$ was read in a MR 700 spectrophotometer (Dynatech). Data were processed by Biolinx software version 2.20 (Dynatech). Calibration curves were constructed by use of increasing concentrations $(0.44-27.5 \mathrm{ng} / \mathrm{ml})$ of recombinant mouse MIS.

\section{Acknowledgments}

We thank Allan Bradley for the AB-1 ES and SNL 76/7 STO cell lines, Corinne Belville for help in mouse MIS purification, and Yoshiko and Kanade Mishina for encouragement. This work was supported by grants from the National Institutes of Health (HD30284 to R.R.B. and CA60651 to M.M.M.), National Cancer Institute, and the Sid W. Richardson Foundation to R.R.B. Rodolfo Rey is recipient of a postdoctoral fellowship of the Consejo Nacional de Investigaciones Científicas y Técnicas (CONICET), Argentina.

The publication costs of this article were defrayed in part by payment of page charges. This article must therefore be hereby marked "advertisement" in accordance with 18 USC section 1734 solely to indicate this fact.

\section{References}

Attisano, L., J.L. Wrana, S. Cheifetz, and J. Massagué. 1992. Novel activin receptors: Distinct genes and alternative mRNA splicing generate a repertoire of serine/threonine kinase receptors. Cell 68: 97-108.

Attisano, L., J. Cárcamo, F. Ventura, F.M.B. Weis, J. Massagué, and J.L. Wrana. 1993. Identification of human activin and TGF $\beta$ type I receptors that form heterodimeric kinase complexes with type II receptors. Cell 75: 671-680.

Baarends, W.M., M.J.L. van Helmond, M. Post, J.C.M. van der Schoot, J.W. Hoogerbrugghe, J.P. de Winter, J.T.J. Uilenbroek, B. Karels, L.G. Wilming, J.H.C. Meijers, A.P.N. Themmen, and J.A. Grootegoed. 1994. A novel member of the transmembrane serine/threonine kinase receptor family is specifically expressed in the gonads and in mesenchymal cells adjacent to the Müllerian duct. Development 120: 189197.

Baarends, W.M., J.W. Hoogerbrugghe, M. Post, J.A. Visser, D.G. de Rooij, M. Parvinen, A.P.N. Themmen, and J.A. Grootegoed. 1995a. Anti-Müllerian hormone and anti-Müllerian hormone type II receptor messenger ribonucleic acid expression during postnatal testis development and in the adult testis of the rat. Endocrinology 136: 5614-5622.

Baarends, W.M., J.T.J. Uilenbroek, P. Kramer, J.W. Hoogerbrugghe, J.P. de Winter, B. Karels, L.G. Wilming, E.C.M. van Leeuwen, A.P.N. Themmen, and J.A. Grootegoed. 1995b. Anti-Mülerian hormone and anti-Müllerian hormone type II receptor messenger ribonucleic acid expression in rat ovaries during postnatal development, the estrous cycle, and gonadotropin-induced follicle growth. Endocrinology 136: 49514962.

Behringer, R.R., R.L. Cate, G.J. Froelick, R.D. Palmiter, and R.L. Brinster. 1990. Abnormal sexual development in transgenic mice chronically expressing Müllerian inhibiting substance. Nature 345: 167-170.

Behringer, R.R., M.J. Finegold, and R.L. Cate. 1994. Müllerianinhibiting substance function during mammalian sexual development. Cell 79: 415-425.

Bradley, A. 1987. Production and analysis of chimeric mice. In Teratocarcinomas and embryonic stem cells: A practical approach (ed. E.J. Robertson), pp. 113-151. IRL Press, Oxford, UK.

Carré-Eusèbe, D., S. Imbeaud, M. Harbison, M.I. New, N. Josso, and J.-Y. Picard. 1992. Variants of the anti-Müllerian hormone gene in a compound heterozygotes with the persistent Müllerian duct syndrome and his family. Hum. Genet. 90: 389-394.

Chomczynski, P. and N. Sacchi. 1987. Single-step method of RNA isolation by acid guanidinium thiocyanate-phenol- 
chloroform extraction. Anal. Biochem. 162: 156-159.

Cohen-Haguenauer, O., J.-Y. Picard, M.G. Mattei, S. Serero, V.C. Nguyen, M.F. de Tand, D. Guerrier, M.C. Hors-Cayla, N. Josso, and J. Frézal. 1987. Mapping of the gene for antiMüllerian hormone to the short arm of human chromosome 19. Cytogenet. Cell. Genet. 44: 2-4.

di Clemente, N., C. Wilson, E. Faure, L. Boussin, P. Carmillo, R. Tizard, J.-Y. Picard, B. Vigier, N. Josso, and R. Cate. 1994. Cloning, expression, and alternative splicing of the receptor for anti-Müllerian hormone. Mol. Endocrinol. 8: 1006-1020.

Ebner, R., R.-H. Chen, L. Shum, S. Lawler, T.F. Zioncheck, A. Lee, A.R. Lopez, and R. Derynck. 1993. Cloning of a type I TGF $\beta$ receptor and its effect on TGF $\beta$ binding to the type II receptor. Science 260: 1344-1348.

Franzén, P. P. ten Dijke, H. Ichijo, H. Yamshita, P. Schul, C.-H. Heldin, and K. Miyazono. 1993. Cloning of a TGF $\beta$ type I receptor that forms a heteromeric complex with the TGF beta type II receptor. Cell 75: 681-692.

Franzén, P., C.-H. Heldin, and K. Miyazono. 1995. The GS domain of the transforming growth factor-beta type I receptor is important in signal transduction. Biochem. Biophys. Res. Comm. 207: 682-689.

Guerrier, D., D. Tran, J.M. Vanderwinden, S. Hideux, L. Van Outryve, L. Legeai, M. Bouchard, V.G. Van, J.-Y. Picard, A. Kahn, and N. Josso. 1989. The persistent Müllerian duct syndrome: A molecular approach. J. Clin. Endocrinol. Metab. 68: $46-52$.

Hacker, A., B. Capel, P. Goodfellow, and R. Lovell-Badge. 1995. Expression of Sry, the mouse sex determining gene. Development 121: 1603-1614.

He, W.W., M.L. Gustafson, S. Hirobe, and P.K. Donahoe. 1993. Developmental expression of four novel serine/threonine kinase receptors homologous to the activin/transforming growth factor-beta type II receptor family. Dev. Dyn. 196: 133-142.

Imbeaud, S., D. Carreàbe, R. Rey, C. Belville, N. Josso, and J.-Y. Picard. 1994. Molecular genetics of the persistent Müllerian duct syndrome: A study of 19 families. Hum. Mol. Genet. 3: 125-131.

Imbeaud, S., E. Faure, I. Lamarre, M.-G. Mattéi, N. di Clemente, R. Tizzard, D. Carré-Eusèbe, C. Belville, L. Tragethon, C. Tonkin, J. Nelson, M. McAuliffe, J.-M. Bidat, A. Lababidi, N. Josso, R.L. Cate, and J.-Y. Picard. 1995. Insensitivity to antiMüllerian hormone due to a mutation in the human antiMüllerian hormone receptor. Nature Genet. 11: 382-388.

Imbeaud, S., C. Belville, L. Messika-Zeitoin, R. Rey, N. di Clemente, N. Josso, and J.-Y. Picard. 1996. A 27 base-pair deletion of the anti-Müllerian type II receptor gene is the most common cause of the persistent Müllerian duct syndrome. Hum. Mol. Genet. (in press).

Josso, N., R.L. Cate, J.-Y. Picard, B. Vigier, N. di Clemente, C. Wilson, S. Imbeaud, R.B. Pepinsky, D. Guerrier, L. Boussin, L. Legeai, and D. Carré-Eusèbe. 1993. Anti-Müllerian hormone the Jost factor. Recent Prog. Horm. Res. 48: 1-59.

Jost, A. 1953. Problems of fetal endocrinology: The gonadal and hypophyseal hormones. Recent Prog. Horm. Res. 8: 379418.

Kaufman, M.H. 1990. In Postimplantation mammalian embryos, a practical approach (ed. A.J. Copp and D.L. Cockroft), pp. 81-91. IRL Press, Oxford, UK.

Kingsley, D.M. 1994. The TGF- $\beta$ superfamily: New members, new receptors, and new genetic tests of function in different organisms. Genes \& Dev. 8: 133-146.

Knebelmann, B., L. Boussin, D. Guerrier, L. Legeai, A. Kahn, N. Josso, and J.-Y. Picard. 1991. Anti-Müllerian hormone Bruxelles: A non-sense mutation in the last exon of the anti-
Müllerian hormone gene associated with the persistent Müllerian duct syndrome in three brothers. Proc. Natl. Acad. Sci. 88: 3767-3771.

Koenig B.B., J.S. Cook, D.H. Wolsing, J. Ting, J.P. Tiesman, P.E. Correa, C.A. Olson, A.L. Pecquet, F. Ventura, R.A. Grant, G.-X. Chen, J.L. Wrana, J. Massagué, and J.S. Rosenbaum. 1994. Characterization and cloning of a receptor for BMP-2 and BMP-4 from NIH 3T3 cells. Mol. Cell. Biol. 14: 59615974.

Lyet, L., F. Louis, M.G. Forest, N. Josso, R.R. Behringer, and B. Vigier. 1995. Ontogeny of reproductive abnormalities induced by deregulation of anti-Müllerian hormone expression in transgenic mice. Biol. Reprod. 52: 444-454.

McMahon, A.P. and A. Bradley. 1990. The Wnt-1 (int-1) protooncogene is required for development of a large region of the mouse brain. Cell 62: 1073-1085.

Mansour, S.L., K.R. Thomas, and M.R. Capecchi. 1988. Disruption of the proto-oncogene int-2 in mouse embryo-derived stem cells: A general strategy for targeting mutations to nonselectable genes. Nature 336: 348-352.

Massagué, J., L. Attisano, and J.L. Wrana. 1994. The TGF- $\beta$ family and its composite receptors. Trends Cell Biol. 4: 172178.

Matsuzaki, K., J. Xu, F. Wang, W.L. McKeehan, L. Krummen, and M. Kan. 1993. A widely expressed transmembrane serine/threonine kinase that does not bind activin, inhibin, transforming growth factor $\beta$, or bone morphogenetic factor. I. Biol. Chem. 268: 12718-12723.

Matzuk, M.M., M.J. Finegold, J.-G.J. Su, A.J.W. Hsueh, and A. Bradley. 1992. $\alpha$-Inhibin is a tumour-suppressor gene with gonadal specificity in mice. Nature 360: 313-319.

Matzuk, M.M., M.J. Finegold, Y. Mishina, A. Bradley, and R.R. Behringer. 1995a. Synergistic effects of inhibins and Müllerian-inhibiting substance on testicular tumorigenesis. Mol. Endocrin. 9: 1337-1345.

Matzuk, M.M., T.R. Kumar, and A. Bradley. 1995b. Different phenotypes for mice deficient in either activins or activin receptor type II. Nature 374: 356-360.

Matzuk, M.M., T.R. Kumar, A. Vassalli, J.R. Bickenbach, D.R. Roop, R. Jaenisch, and A. Bradley. 1995c. Functional analysis of activins during development. Nature 374: 354-356.

Meyers-Wallen, V.N., P.K. Donahoe, S. Ueno, T.F. Manganaro, and D.F. Patterson. 1989. Müllerian inhibiting substance is present in testes of dogs with persistent Müllerian duct syndrome. Biol. Reprod. 41: 881-888.

Mishina, Y., A. Suzuki, N. Ueno, and R.R. Behringer. 1995. $B m p r$ encodes a type I bone morphogenetic protein receptor that is essential for gastrulation during mouse embryogenesis. Genes \& Dev. 206: 310-317.

Münsterberg, A., and R. Lovell-Badge. 1991 Expression of the mouse anti-Müllerian hormone gene suggests a role in both male and female sexual differentiation. Development 113: 613-624.

Naguib, K.K., A.S. Teebi, S.A. Al-Awadi, M.Y. El-Khalifa, and E.S. Mahfouz. 1989. Familial uterine hernia syndrome: Report of an Arab family with four affected males. Am. J. Hum. Genet. 33: 180-181.

Sloan, W.R. and P.C. Walsh. 1976. Familial persistent Müllerian duct syndrome. J. Urol. 115: 459-461.

Soriano, P., C. Montgomery, R. Geske, and A. Bradley. 1991. Targeted disruption of the $c$-src proto-oncogene leads to osteopetrosis in mice. Cell 64: 693-702.

Suzuki, A., N. Shioda, T. Maeda, M. Tada, and N. Ueno. 1994. A mouse TGF- $\beta$ type I receptor that requires type II receptor for ligand binding. Biochem. Biophys. Res. Comm. 298: 1063-1069. 
Teixeira, J., W.W. He, P.C. Shah, N. Morikawa, M.M. Lee, E.A. Catlin, P.L. Hudson, J. Wing, D.T. Maclaughlin, and P.K. Donahoe. 1996. Developmental expression of a candidate Müllerian inhibiting substance type II receptor. Endocrinology 137: 160-165.

ten Dijke, P., H. Ichijo, P. Franzén, P. Schulz, J. Saras, H. Toyoshima, C.-H. Heldin, and K. Miyazono. 1993. Activin receptor-like kinases: A novel subclass of cell-surface receptors with predicted serine/threonine kinase activity. Oncogene 8: 2879-2887.

ten Dijke, P., H. Yamashita, T.K. Sampath, A.H. Reddi, M. Estevez, D.L. Riddle, H. Ichijo, C.-H. Heldin, and K. Miyazono. 1994. Identification of type I receptors for osteogenic protein-1 and bone morphogenetic protein-4. I. Biol. Chem. 269: 16985-16988.

Vale, W., A. Hsueh, C. Rivier, and J. Yu. 1990. The inhibin/ activin family of hormones and growth factors. In Peptide growth factors and their receptors II (ed. M.B. Sporn and A.B. Roberts), pp. 211-248. Springer-Verlag, Germany.

Vassalli, A., M.M. Matzuk, H.A.R. Gardner, K.-F. Lee, and R. Jaenisch. 1994. Activin/inhibin $\beta B$ subunit gene disruption leads to defects in eyelid development and female reproduction. Genes \& Dev. 8: 414-427.

Vigier, B., J.-Y. Picard, D. Tran, L. Legai, and N. Josso. 1984. Production of anti-Müllerian hormone: Another homology between Sertoli and granulosa cells. Endocrinology 114: 1315-1320.

Vigier, B., F. Watrin, S. Magre, D. Tran, and N. Josso. 1987. Purified bovine AMH induces a characteristic freemartin effect in fetal rat prospective ovaries exposed to it in vitro. Development 100: 43-55.

Visser, J.A., A. McLuskey, T. van Beers, D.O. Weghuis, A.G. van Kessel, J.A. Grootegoed, and A.P. Themmen. 1995. Structure and chromosomal localization of the human anti-Müllerian hormone type II receptor gene. Biochem. Biophys. Res. Commun. 215: 1029-1036.

Winnier, G., M. Blessing, P.A. Labosky, and B.L.M. Hogan. 1995. Bone morphogenetic protein-4 (BMP-4) is required for mesoderm formation and patterning in the mouse. Genes \& Dev. 9: 2105-2116.

Wrana, J.L., L. Attisano, R. Wieser, F. Ventura, and J. Massagué. 1994. Mechanism of activation of the TGF- $\beta$ receptor. $\mathrm{Na}$ ture 370: 341-347.

Yamaii, N., A.J. Celeste, R.S. Thies, J.J. Song, S.M. Bernier, D. Goltzman, K.M. Lyons, J. Nove, V. Rosen, and J.M. Wozney. 1994. A mammalian serine/threonine kinase receptor specifically binds BMP-2 and BMP-4. Biochem. Biophys. Res. Comm. 205: 1944-1951.

Zhang, H. and A. Bradley. 1996. Mice deficient for BMP-2 are non-viable and have defects in amnion/chorion and cardiac development. Development 122: 2977-2986. 


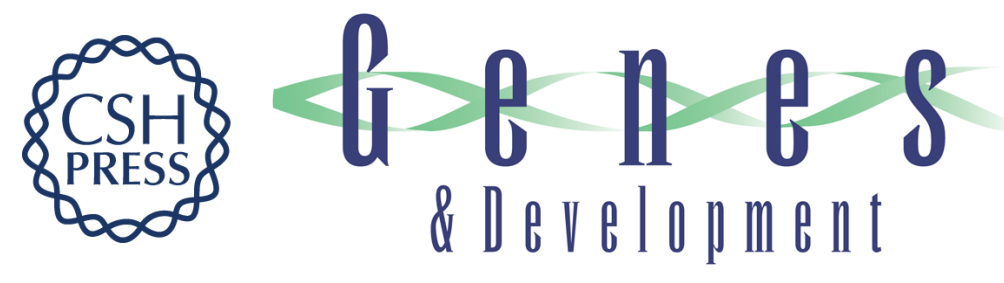

\section{Genetic analysis of the Müllerian-inhibiting substance signal transduction pathway in mammalian sexual differentiation.}

Y Mishina, R Rey, M J Finegold, et al.

Genes Dev. 1996, 10:

Access the most recent version at doi:10.1101/gad.10.20.2577

References This article cites 51 articles, 12 of which can be accessed free at: http://genesdev.cshlp.org/content/10/20/2577.full.html\#ref-list-1

License

Email Alerting

Receive free email alerts when new articles cite this article - sign up in the box at the top Service right corner of the article or click here.

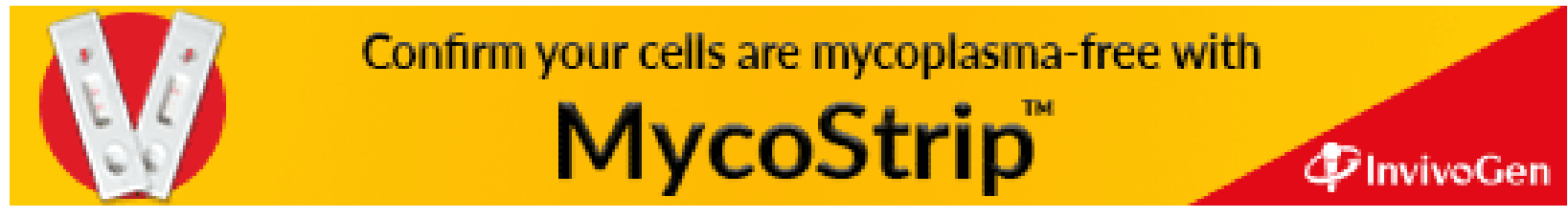

